\title{
A HOLISTIC CONCEPTION OF SUSTAINABLE BANKING: ADDING VALUE WITH FUZZY COGNITIVE MAPPING
}

\author{
Daniela CARLUCCI ${ }^{1}$, Fernando A. F. FERREIRA ${ }^{2 *}$, Giovanni SCHIUMA ${ }^{3}$, \\ Marjan S. JALALI ${ }^{4}$, Nelson J. S. ANTÓNIO ${ }^{5}$ \\ ${ }^{1}$ Department of European and Mediterranean Cultures, Environment and Cultural Heritage (DICEM), \\ University of Basilicata, Via San Rocco 3, 75100 Matera, Italy \\ ${ }^{2}$ ISCTE Business School, BRU-IUL, University Institute of Lisbon, Avenida das Forças Armadas, \\ 1649-026 Lisbon, Portugal \& Fogelman College of Business and Economics, \\ University of Memphis, Memphis, TN 38152-3120, USA \\ ${ }^{3}$ Department of Mathematics, Computer Sciences and Economics (DIMIE), \\ University of Basilicata, Via dell'Ateneo Lucano 10, 85100, Potenza, Italy \& \\ Innovation Insights Hub, University of the Arts London, King's Cross, London, UK \\ ${ }^{4,5}$ ISCTE Business School, BRU-IUL, University Institute of Lisbon, Avenida das Forças Armadas, \\ 1649-026 Lisbon, Portugal
}

Received 30 November 2015; accepted 25 November 2016

\begin{abstract}
Integrating sustainability into the banking activity is an increasingly necessary but extremely challenging issue currently facing financial institutions. It is therefore becoming ever more important to understand the key determinants of sustainable banking and how they inter-relate with each other. This research aims to build a cognitive map - a fuzzy cognitive map (FCM) in particular - to model, dynamically analyze and test the reciprocal influence of key factors underlying sustainable banking. FCMs have been shown to be particularly useful for handling complex decision problems characterized by lack of information or unavailable data. They constitute a methodological framework that allows for a reduction of omitted determinants - in this case, with regard to sustainable banking - and are typically able to provide a greater understanding of the cause-and-effect relationships between such determinants. We anticipate implications and practical applications for both bank managers and policymakers aiming to increase the efficiency of their decision making in the context of sustainable banking.
\end{abstract}

Keywords: sustainable banking, holistic view, problem structuring methods, fuzzy cognitive maps, knowledge management, expert systems.

JEL Classification: C44, C45, M10.

*Corresponding author. E-mails: fernando.alberto.ferreira@iscte.pt; fernando.ferreira@memphis.edu 


\section{Introduction}

The 21st century has brought greater business diversification to the banking industry, such that most of the major banks in the industrialized world are now complex financial organizations offering a wide range of services to international markets, and strategically controlling billions of dollars in cash and assets. Making use of technological advances, banks have been working to identify new market opportunities, implement new strategies, and increase their levels of customer retention (Reis et al. 2013). As the globalization and diversification of the financial industry increase, such actions have become increasingly challenging; and as banks operate in more complex and rapidly changing environments, competition becomes more fierce, and the need to adapt ever more pressing (Cole 2011; Ferreira et al. 2012; Stankevičienè, Nikonorova 2014; Jalali et al. 2016). It is anticipated that over the coming years the banking sector will become even more convoluted, leading to local adaptations in the manner in which banks operate around the world.

The requirement for survival, then, is a posture of learning, whereby banks are able to adapt to the demands of the external environment with ever greater agility. At the same time, from an academic point of view, it becomes increasingly pressing to understand the effects of these ongoing changes in the global economy, as well as the role of banks - how they affect and are affected by these changes - in particular. This is of particular relevance, given banks' increasing importance in the business community (Stephens, Skinner 2013; Ferreira et al. 2014).

It is against this background of change that growing discussions about the integration of sustainability into the banking activity, in both academia and business practice, have been set. Recent analyses have shown that sustainable, values-based banks, which try to base their decisions taking into account the triple bottom line, thus considering the needs of people and the environment in addition to profit, are often outperforming traditional mainstream banks in terms of financial indicators such as return on assets or growth in loans and deposits (for a fuller discussion, see Rebai et al. 2012; Fatemi, Fooladi 2013; Stephens, Skinner 2013; Ferreira et al. 2015). Such results have put sustainability at the forefront of banks' managerial concerns, and at the same time made researching sustainable banking an imperative.

The integration of sustainability concerns in banking has essentially been taking two forms: (1) socially and environmentally responsible initiatives (e.g. support for cultural events, charitable donations, recycling programs and support for improvements in energy efficiency); and (2) the integration of environmental and social considerations into product design, mission and business strategies (e.g. the integration of environmental criteria into lending and investment strategies) (Jeucken, Bouma 1999; Bouma et al. 2001). This second dimension highlights the potential impact of incorporating sustainability into banks' competitive strategies and decision-making processes on a larger scale, since financing environmentally and socially responsible projects can ultimately lead to changes in the business landscape as whole, as sustainable and sound enterprises are helped to prosper (Stephens, Skinner 2013). Indeed, a major shift has already happened, as banks have come to realize that poor environmental and social performance on the part of their clients can represent 
a threat to their own profitability. There is an increasing concern among banks over clients' environmental and social performance, which has been acting as an additional driver of sustainable banking, leading banks to develop mechanisms to assess their customers' ethical and environmental risk exposure, in order to protect themselves from potential losses.

Despite the above arguments, integrating wider stakeholder concerns (including the environment) into the banking activity is not as simple as it might appear. In fact, given the considerable number of decision makers involved, and the large variety of sustainability determinants to be considered, this integration often proves a very challenging undertaking. It becomes imperative, therefore, to understand these determinants of banking sustainability, and how they inter-relate with each other, to promote (or inhibit) the integration of sustainability in banks' strategic decisions. A fuller understanding of this hitherto largely underdeveloped topic is not only of academic interest, but can be of great utility to the decision makers involved. Indeed, a better understanding of the determinants of sustainability can help both bank managers and policy makers make more informed decisions about sustainable value creation. Ultimately, it can be expected to help support not only the development of more sustainable banking, but more sustainable business ventures in general.

Our first research question thus pertains to the key determinants of sustainable banking and the manner in which they inter-relate with each other. Identifying and understanding the conditions that underpin sustainable banking and clarifying the links between them is crucial to the enhancement of value creation and achieving the desired sustainability goals. Existing research on these conditions or indicators "is yet speculative, due to a shortage of standard definitions and relevant data" (Kauko 2010: 191), which highlights the need to not only identify them, but also to develop a framework for their representation and categorization, such that they can better be used to create value. Our second research question thus seeks to determine whether a knowledge-based representation of sustainable banking can be created, and having been developed, whether such a framework can enhance value creation.

In seeking to analyze these questions, an approach using Fuzzy Cognitive Maps (FCMs) is employed. This approach simultaneously allows for the pursuit of a third research goal, which is to test the applicability of FCMs in the context of sustainable banking. FCMs have previously proven useful in handling complex decision problems characterized by lack of information or unavailable data (Carlucci et al. 2013; Gavrilova et al. 2013; Ferreira et al. 2015). Indeed, "FCM is a well-established artificial intelligence technique, incorporating ideas from artificial neural networks and fuzzy logic, which can be effectively applied in the domain of management science" (Carlucci et al. 2013: 208). This methodological framework should allow not only for a reduction in the number of omitted determinants, but also for a greater understanding of the cause-and-effect relationships between the determinants identified.

Although the FCM approach allows for static, dynamic and loop analyses to model dynamic systems, it can also be used for (simple) knowledge representation and understanding (Carlucci et al. 2014; Peng et al. 2016) - and this is the manner in which it is applied in the current study. Rather than analyzing system dynamics in great detail, our focus in this study is on the cognitive structure of the factors affecting sustainable banking. The epistemological stance thus taken differentiates our work from the extant literature report- 
ing FCM applications, which has generally been more focused on the analysis of variable dynamics, rather than on knowledge sharing and representation per se.

The remainder of the paper is structured as follows. The next section presents a brief review of the literature on sustainable banking. Section two presents the research problem and the methodological background. Section three explains the steps followed during the construction of our FCM, and the final section concludes the paper.

\section{Previous studies on sustainable banking}

It is commonly accepted that recent economic crises have triggered a sharp increase in competition across most industries (e.g. Ferreira et al. 2011; Ramos et al. 2011; Stankevičiené, Nikonorova 2014). Wu (2012: 303) refers to the "chain effects of the financial 'tsunami" that was the Global Financial Crisis, and the fact that "financial institutions in particular have encountered more competitive challenges worldwide" as a result of it. In such a climate, it becomes increasingly necessary for financial and banking institutions to have clear and clearly understood visions and missions on the basis of which they can determine the strategies and tactics that will be used to achieve their objectives (Ferreira et al. 2012). This implies substantial progress in banks' abilities to mobilize, explore and evaluate tangible and intangible resources, in line with the opportunities offered by their (ever changing) context.

Indeed, as noted by Carmeli (2004: 111-112), in turbulent contexts, "the real source of competitive advantage is underlined by the organization's ability to consistently meet environmental changes". And one of the key demands from the external environment in recent times appears to be that of sustainability. This suggests banks need to develop the organizational agility to integrate sustainability concerns into their strategic decision-making processes in a sustained and systematic way. Simply performing traditional activities, such as attracting and investing savings, is arguably no longer enough. New responsibilities environmental and social - are demanded of banks; and the best way forward may well be to look at these as business opportunities, rather than risk factors.

Delineating and implementing a "sustainability strategy" to address this arising opportunity is only possible when there is an ability and willingness to consider and involve stakeholders in decision-making processes. The challenge arises, however, from the considerable number of stakeholders potentially involved (see Fig. 1) and the fact that they do not necessarily have the same interests and priorities. As a result, decision processes, those pertaining to sustainability in particular, are unlikely to be easy.

A further challenge emerges when it becomes apparent from the literature that the determinants of sustainable banking have not yet been clearly identified, let alone defined and understood (Kauko 2010; Ferreira et al. 2016). Understanding these determinants and their relative importance, however, is fundamental to our comprehension of banks' ability to consider sustainability in a strategic manner. This integration of sustainability in banking further implies a solid long-term commitment on the part of bank managers toward the creation of both value and a more responsible society.

Given the social and economic relevance of this issue, it is not surprising that it has been attracting increasing interest in the literature (Jeucken, Bouma 1999; Bouma et al. 2001; 


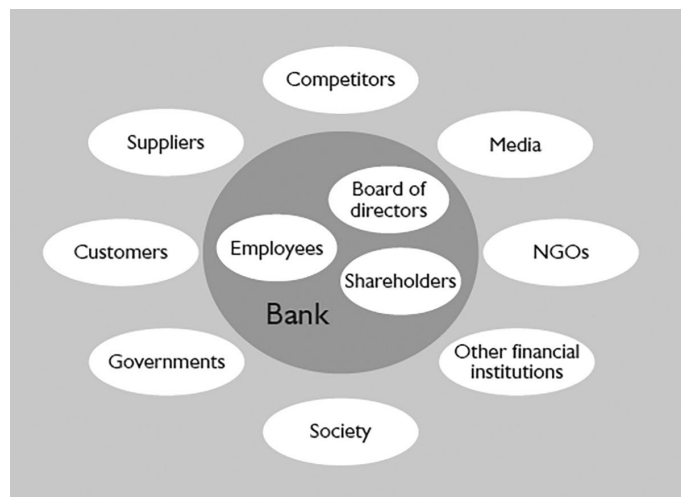

Figure 1. Sustainability strategy and (internal and external) stakeholders Source: Jeucken and Bouma (1999).

Rebai et al. 2012; Fatemi, Fooladi 2013; Stephens, Skinner 2013). However, and the undeniable merit of such contributions notwithstanding, there is still a need to more fully identify and define the determinants of sustainable banking, and the relationships between them. Indeed, most of the existing research presents the end results of sustainable banking practices, but does not explain why they emerge or how they can be improved. Furthermore, most of the extant research relies on parametric analyses, which, it has been argued, may have limited ability to provide practical contributions to sustainable relationship management (Garland, Gendall 2004; Ferreira et al. 2011). In particular, the process by which the determinants of sustainable banking are identified and articulated in such studies has been posited to be somewhat arbitrary (Pan et al. 2012).

Given these limitations, the recourse to modern approaches, such as FCMs and neural networks, constitutes a promising avenue in the field of sustainable banking. Although naturally not without their own limitations, these "new" approaches hold the potential to identify the "missing links" between determinants, and consequently enhance value creation by increasing the transparency and our understanding of decision situations.

Our framework sees sustainable banking as a complex decision problem, where the determinants of sustainability are strongly dependent on diverse stakeholders with different and conflicting values and preferences. As such, it assumes a process-oriented position and is developed with the direct involvement of professionals from the banking industry.

\section{Research problem and methodological background}

\subsection{Research problem}

This study aims to analyze the conditions and key determinants that support sustainable banking. A better understanding of these determinants, and the ways in which they are interlinked, can help bank managers and other decision makers to enhance value creation through more informed decisions, at the same time as sustainability objectives are moved forward. 


\subsection{General overview of the methodology}

Although there can be many ways to consider decision problems and decision-making situations, when these are multifaceted and multiple criteria are involved, additional demands are placed on the methodological approach adopted to analyze them. Cognitive mapping has been argued to be particularly suited to such situations, not only because it allows for the modeling of complex relationships between variables in manifold phenomena (Carlucci et al. 2013; Canas et al. 2015; Martins et al. 2015), but also because, as visual tools, maps "support the identification and the interpretation of information, facilitate consultation and codification, and stimulate mental associations" (Gavrilova et al. 2013: 1758). Indeed, by directly involving participants and fostering discussion between them in order to come to a consensual group map, this methodology promotes greater processual transparency, improves understanding of the decision problem and reduces the likelihood of omitted variables (Peña et al. 2008; Ferreira et al. 2012; Filipe et al. 2015; Jalali et al. 2016).

Within cognitive mapping, "Fuzzy Cognitive Maps" (Kosko 1986, 1992) in particular have been extensively applied to contexts and decision problems characterized by high levels of complexity (e.g. Kardaras, Mentzas 1997; Stylios, Groumpos 1999; Tsadiras et al. 2003; Kok 2009; Salmeron 2009; Papageorgiou et al. 2012; Salmeron 2012; Carvalho 2013; Papageorgiou, Salmeron, 2013; Yesil et al. 2013; Dias et al. 2015; Ferreira, Jalali 2015; Vidal et al. 2015). One of the method's features/advantages lies in complementing cognitive mapping with fuzzy logic. In FCMs, relationships between criteria can be represented by positive and negative causality at the same time; the intensity of which is then translated into a number which can go from -1 to 1 . The resulting map thus allows for dynamism, by including feedback links between the different variables/criteria (Carlucci et al. 2013), as represented in Figure 2, where $C_{i}$ is criterion or variable $i$ and $w_{i j}$ represents the extent to which criterion $i$ influences criterion $j$. This relationship $\left(w_{i j}\right)$ can be of positive, negative or null causality, depending on whether $C_{i}$ causes a move in the same direction, the opposite direction or has no impact on $C_{j}$.

Extensive discussion of the mathematical foundations of the FCM approach and specific examples of its dynamics can be found, for instance, in Kosko (1986), Kim and Lee (1998), Kok (2009), Kang et al. (2012), Lopez and Salmeron (2013), Yesil et al. (2013), Peng et al. (2015) and Vidal et al. (2015). These mathematical foundations can be summarized in Eq. (1), where $A_{i}{ }^{(t+1)}$ is the activation level of criterion $C_{i}$ at time $t+1 ; A_{i}{ }^{(t)}$ is the activation

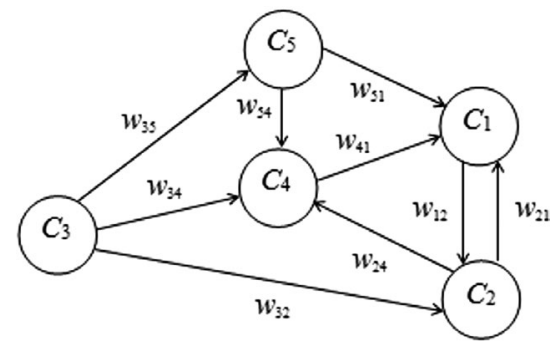

Figure 2. Typical structure of an FCM 
level of criterion $C_{i}$ at time $t ; A_{j}{ }^{(t)}$ is the activation level of criterion $C_{j}$ at time $t ; w_{j i}$ is the weight of the interconnection between both criteria; and $f$ represents a threshold activation function (Mazlack 2009). The most common threshold functions are: (1) tangent hyperbolic $(f(x)=\tan (x))$; (2) sigmoid function $\left(f(x)=1 /\left(1+e^{-x}\right)\right)$; (3) bivalent function $(f(x)=$ 0 or 1); and (4) trivalent function $(f(x)=-1,0$ or 1) (see Stach et al. 2005; Papageorgiou et al. 2012; Glykas 2013).

$$
A_{i}^{(t+1)}=f\left(A_{i}^{(t)}+\sum_{\substack{j \neq i \\ j=1}}^{n} A_{j}^{(t)} \cdot w_{j i}\right) .
$$

Mazlack (2009) clarifies that the overall impact of a change in the value of a particular criterion is given by a new state vector $A_{n e w}$, which is obtained by multiplying the previous state vector $A_{\text {old }}$ by the adjacency matrix $W$. An illustrative example from prior literature (Ferreira, Jalali 2015), considering three different criteria (i.e. $C_{1}, C_{2}$ and $C_{3}$ ), reveals the approach's mathematical dynamics as follows:

- State vector $A_{\text {old }}=(1,0,1)$;

- Adjacency matrix $W=\left(\begin{array}{ccc}0 & 0.5 & 0.1 \\ -0.5 & 0 & 1 \\ 1 & 0.5 & 0\end{array}\right)$;

- New state vector $A_{\text {new }}=A_{\text {old }} \times W=(1,0,1) \times\left(\begin{array}{ccc}0 & 0.5 & 0.1 \\ -0.5 & 0 & 1 \\ 1 & 0.5 & 0\end{array}\right)$;

$$
\begin{aligned}
& =1 \times(0,0.5,0.1)+0 \times(-0.5,0,1)+1 \times(1,0.5,0) ; \\
& =(0,0.5,0.1)+(0,0,0)+(1,0.5,0) ; \\
& =(1,1,0.1) .
\end{aligned}
$$

The transformed vector ( $A_{\text {new }}$ in the example above) "is then repeatedly multiplied by the adjacency matrix and transformed until the system converges to a fixed point. Typically it converges in less than 30 simulation time steps" (Carlucci et al. 2013: 213). Aiming to exemplify this type of exercise, Figure 3 shows the results of a simulation from prior literature (Kok 2009).

A ranking (i.e. "strength of impact") of criteria is then obtained, reflecting how the system is perceived in the FCM. This allows: a) the impact of changes in the value of any single concept to be assessed; b) the strength of the impact of concepts on each other to be determined; and c) "what if" questions to be formulated, in order to ascertain the impact on the system as whole of changes, additions or the removal of concepts.

The most common challenge in applying this kind of methodology relates to the difficulty of getting group members (in this case, experts from banking institutions) together in the same place at the same time, for what are relatively long sessions required to develop a collective cognitive map. Although this is an issue to be taken seriously, we considered that the potential benefits of the application of FCMs to the field of sustainable banking, in terms of contributions to both theory and practice, would outweigh this challenge. 

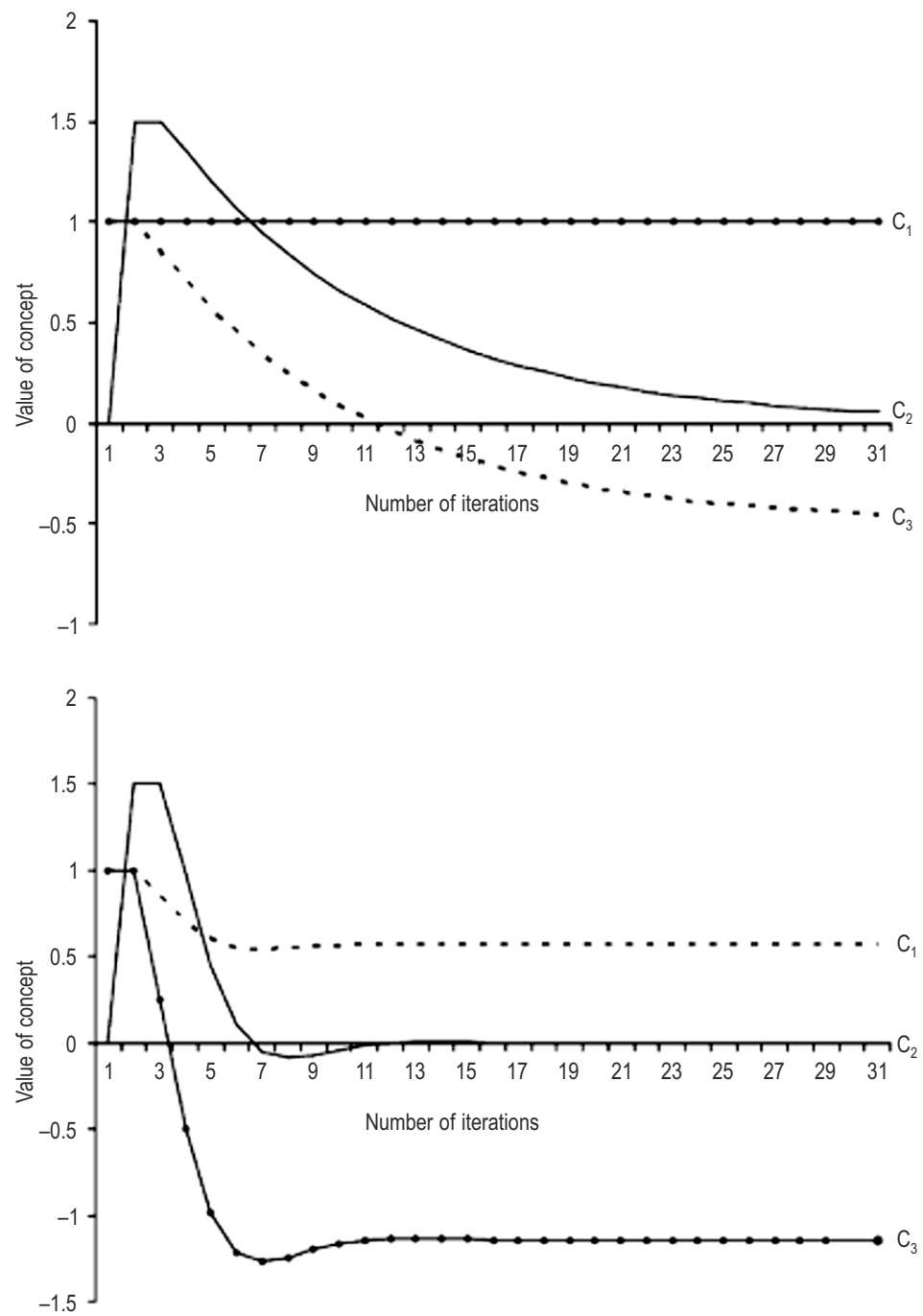

Figure 3. FCM stabilization and value convergence points Source: Kok (2009: 125).

\section{Construction of the fuzzy cognitive map}

In this section we present a step-by-step discussion of how the FCM approach was used to identify the key determinants of bank sustainability. The aim was one of simple knowledge representation (Carlucci et al. 2014; Peng et al. 2016), rather than an analysis of system dynamics in great detail. As such, and in conformity with the constructivist stance assumed, the focus was on the processes of knowledge sharing and learning through which the FCM was developed, allowing participants' understanding of sustainable banking to be structured. 


\subsection{Participants involved}

With regard to the participants, Yaman and Polat (2009: 387) argue that, in this type of study, "using a group of experts has the benefit of improving the reliability of the final model". As such, we sought to set up a professional panel constituted by banking experts. After several unsuccessful attempts, due to availability restrictions and incompatible schedules, we were finally able to form a panel with seven participants. This group was comprised of three regional directors, two bank branch managers and two bank branch front office employees, from the five largest banks operating in Portugal, who all had between 20 to 30 years' experience in the field. Although "the expert panel number is quite difficult to establish and no study has been conclusive with respect to it" (Salmeron 2009: 276), seven can be considered a very reasonable number of participants for this kind of research, in particular since "the consultant [i.e. facilitator] will relate personally to a small number (say, three to ten persons)" (Eden, Ackermann 2001: 22). Furthermore, the group's heterogeneity, in terms of hierarchical levels and the banks to which they were affiliated, allowed different perceptions on sustainable banking to be confronted, enriching the discussions underlying the whole process.

The expert panel was brought together during an intensive 7-hour meeting, which was conducted by an experienced facilitator assisted by an ICT technician. Due to the processoriented nature of this study, it should be noted that the processual steps followed, when properly adjusted, can work well with different groups of participants (for discussion, see Ferreira et al. 2015).

\subsection{Identifying concepts and quantifying relationships}

The group meeting started with an initial clarification of the research objectives and a presentation of the principles of FCM. The aim was to ensure a common understanding of the purpose of the session and its functioning among the participants. Having established this common ground, the group was asked the following trigger question: "Based on your own values and professional experience, what are the determinants of sustainable banking?". This provided the focus for the discussion and allowed the "post-its technique" to be applied. This technique consists of writing what the decision makers consider as relevant criteria on post-its (i.e. one criterion per sticker), and sticking them on a large piece of paper for easy visualization (Ackermann, Eden 2001). The process is grounded on continuous debate among the panel members and should be repeatedly executed until they are collectively satisfied with the outcomes achieved. In the next stage of the process, the panel members then organize the post-its by areas of concern (or clusters), which allows for additional discussion on the meaning and significance of each criterion. Once the areas of concern have been defined, each cluster is then carefully analyzed, so the post-its can be reorganized in a means-end-based structure; i.e. the most important/strategic concepts are put at the top of the cluster and the least important are put at the bottom. Figure 4 illustrates some of these stages. 

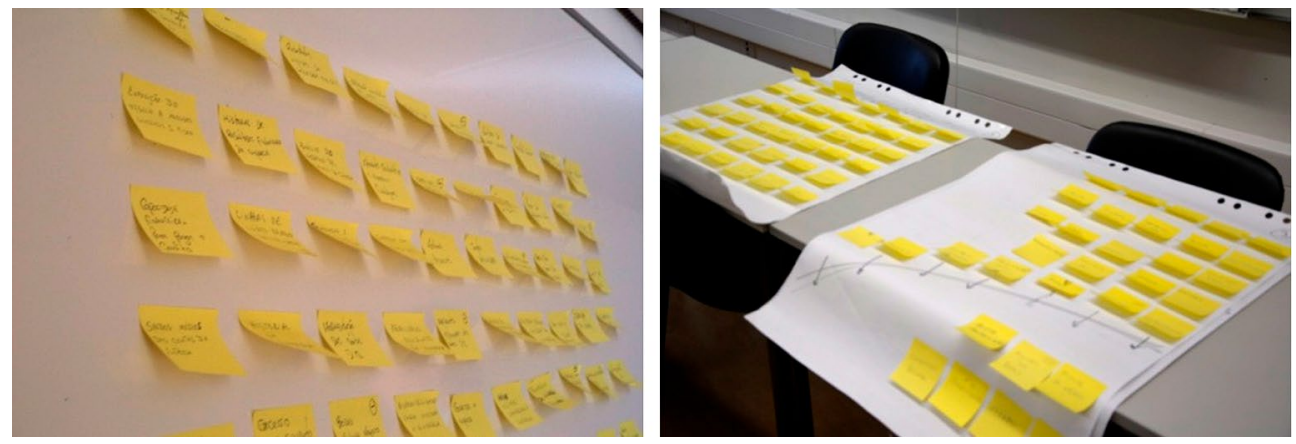

Figure 4. Snapshots of the "post-its session"

Once there is agreement within the group with regard to the form and content of the cognitive structure developed, this phase of the process is considered concluded, and a "strategic" or "collective" map is obtained (cf. Jalali et al. 2016). In our study, the final version of the map, which is illustrated in Figure 5 and represents the group's agreement on the key determinants of sustainable banking, was developed using the Decision Explorer software (www.banxia.com).

The final version of the map contained 167 determinants of sustainable banking (an editable version can be obtained from the authors upon request). Beyond the mere identification of criteria, however, its development process allowed vast amounts of information to be shared, discussed and analyzed, through the insights brought by the experts involved in the process (Ferreira et al. 2014; Jalali et al. 2016). In practical terms, the cognitive map allowed the panel members to be provided with a holistic view of sustainable banking, which they themselves also considered extremely useful.

Moving forward in the construction of the FCM, the agreed upon collective map was rebuilt using the FCMapper (http://www.fcmappers.net) and Pajek software (http://pajek. imfm.si/doku.php). As complements to Decision Explorer, these two software packages allow the intensity of the links between variables to be dynamically analyzed. Figure 6 presents the new layout of the cognitive structure, where each number stands for one of the determinants of sustainable banking previously identified (a full version using concept names instead of numbers can be obtained from the authors upon request).

The panel members were provided with Figure 6 and asked to analyze the intensity of the links. Figure 7 illustrates this analysis, which was performed for all the clusters and where the intensity of each link ranges between -1 and 1 ( $c f$. subsection 2.2 ).

These degrees of intensity expressed by the group were then introduced in a $167 \times 167$ adjacency matrix. Again, size restrictions prevent us from displaying the matrix in this paper. However, Table 1 exemplifies the type of matrix used, where $-1 \leq w_{j i} \leq 1$. 


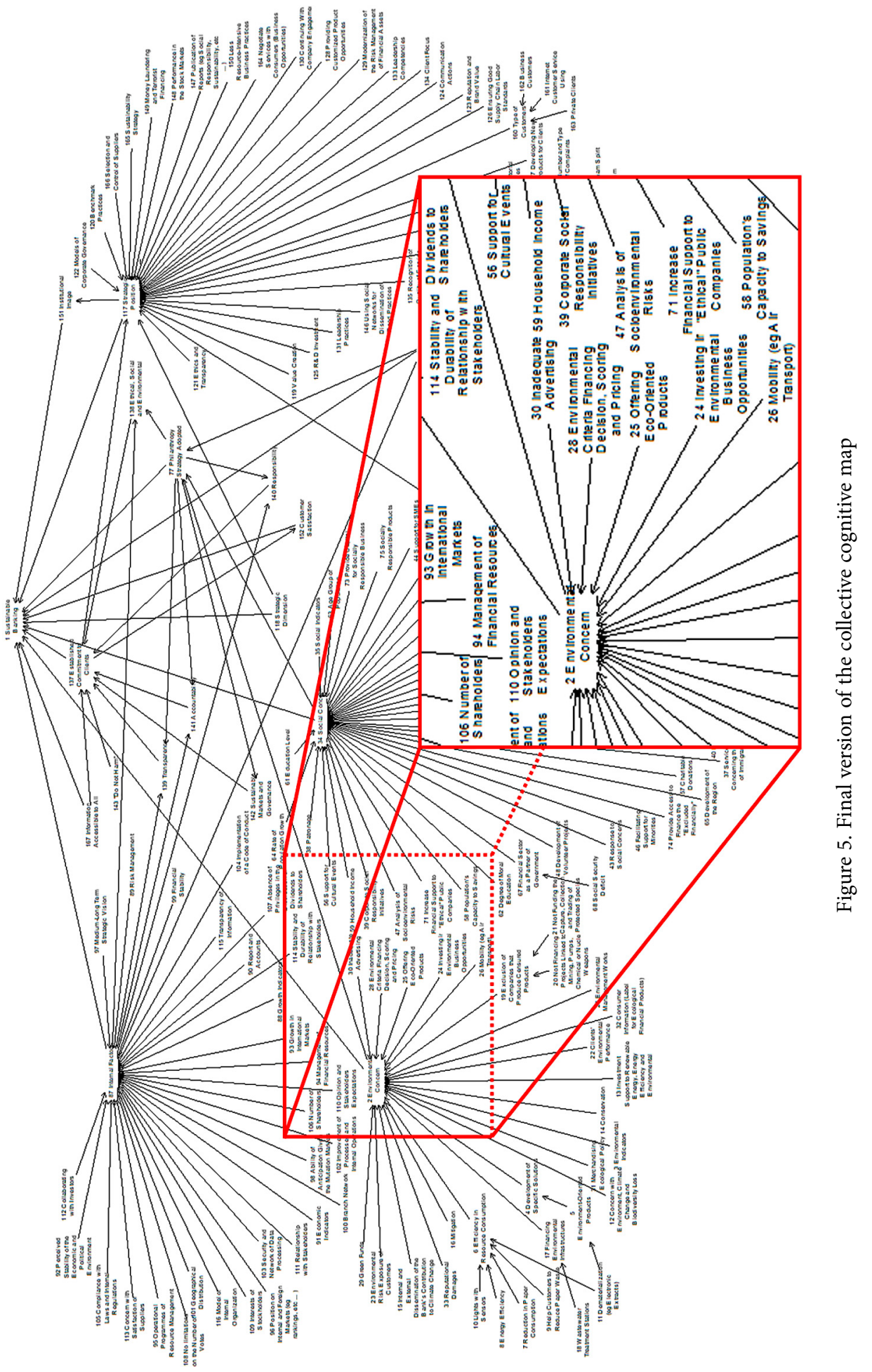




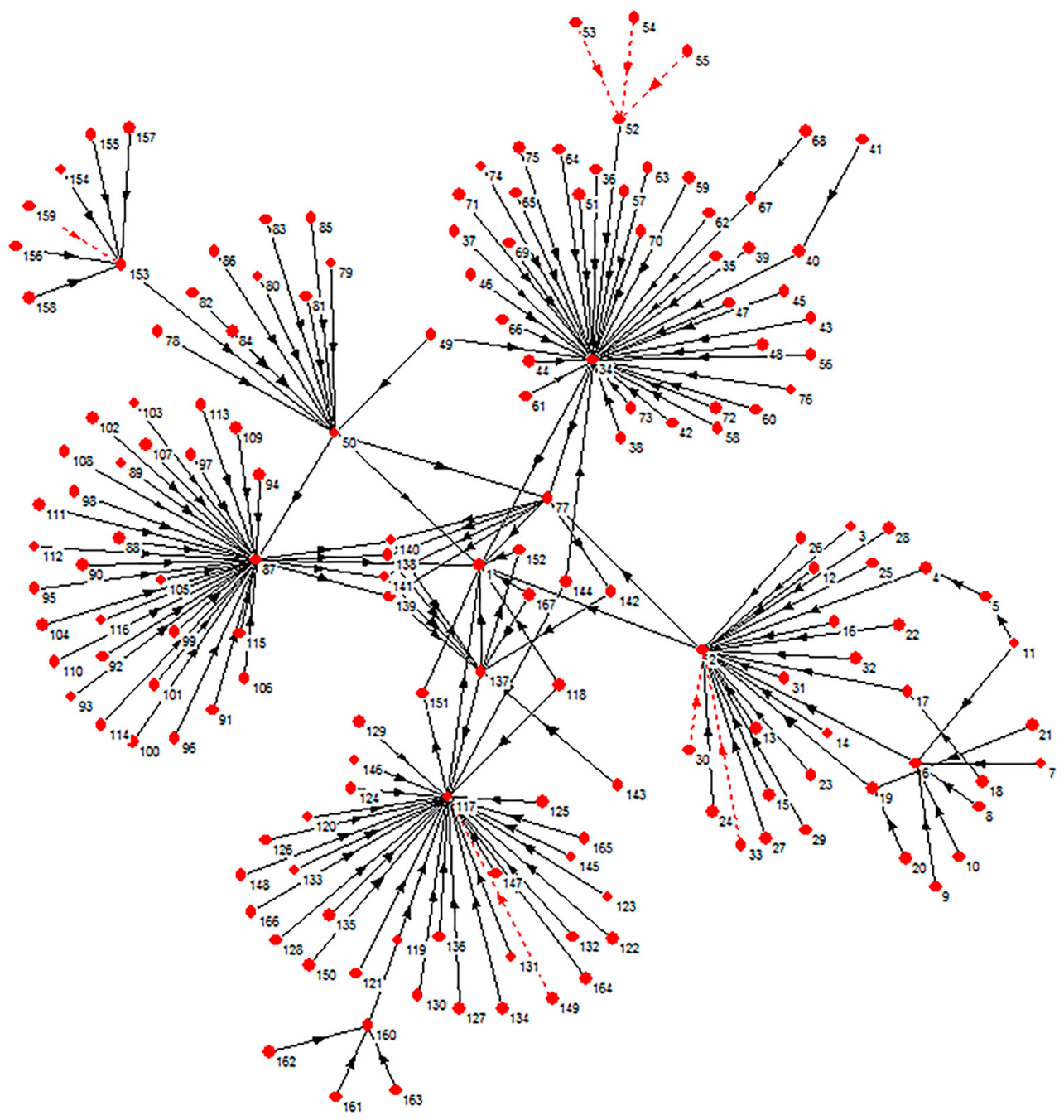

Figure 6. Basic structure of the FCM Source: Carlucci et al. (2014: 1849).

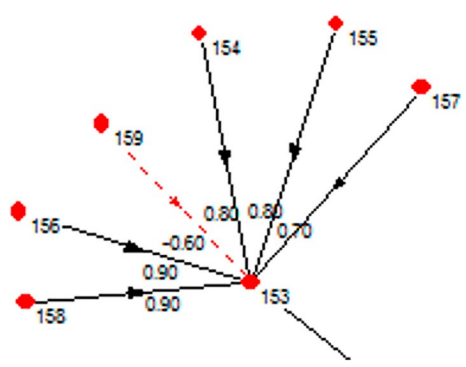

Figure 7. Quantification of relationships Source: Carlucci et al. (2014: 1850). 
Table 1. Adjacency matrix

\begin{tabular}{cccccc}
\hline & $C_{1}$ & $C_{2}$ & $\cdots$ & $C_{n-1}$ & $\mathrm{C}_{\mathrm{n}}$ \\
\hline$C_{1}$ & 0 & $w_{12}$ & $\cdots$ & $w_{1 n-1}$ & $w_{1 n}$ \\
\hline$C_{2}$ & $w_{21}$ & 0 & $\cdots$ & $w_{2 n-1}$ & $w_{2 n}$ \\
\hline$\ldots$ & $\cdots$ & $\cdots$ & $\cdots$ & $\cdots$ & $\cdots$ \\
\hline$C_{n-1}$ & $w_{n-11}$ & $w_{n-12}$ & $\cdots$ & 0 & $w_{n-1 n}$ \\
\hline $\mathrm{C}_{\mathrm{n}}$ & $w_{n 1}$ & $w_{n 2}$ & $\cdots$ & $w_{n n-1}$ & 0 \\
\hline
\end{tabular}

The development of the adjacency matrix served to promote additional discussion regarding the results and helped define the study recommendations (Yaman, Polat 2009; Salmeron 2012; Carlucci et al. 2013; Ferreira et al. 2015).

\subsection{Interpreting the research outputs}

Although not the major concern in this paper, several static, dynamic and loop analyses were carried out throughout the study (and shared with the panel members); and "through a proper neural network computational model, [...] what we can get is an idea of the ranking of the variables in relationship to each other according to how the system is perceived in the FCM" (Carlucci et al. 2013: 216). This criteria interaction allowed the most relevant determinants of sustainable banking to be identified, as presented in Table 2.

Table 2. Major determinants of sustainable banking [based on centrality]

\begin{tabular}{lcccc}
\hline \multicolumn{1}{c}{ Determinants } & Reference & Outdegree & Indegree & Centrality \\
\hline Social Concern & 34 & 1.80 & 28.10 & 29.90 \\
\hline Strategic Position & 117 & 1.79 & 25.20 & 26.90 \\
\hline Internal Factors & 87 & 4.10 & 22.70 & 26.80 \\
\hline Environmental Concern & 2 & 1.50 & 17.40 & 18.90 \\
\hline Human Resources & 50 & 2.40 & 08.90 & 11.30 \\
\hline Commitment to Clients & 137 & 2.59 & 06.10 & 08.69 \\
\hline Philanthropy Strategy Adopted & 77 & 5.00 & 02.60 & 07.60 \\
\hline
\end{tabular}

Source: Adapted from Carlucci et al. (2014: 1851).

A centrality index was calculated for each criterion comprised in the FCM. Due to the high number of criteria (i.e. 167), only the ones with the greatest indices were included in Table 2 (a copy of the entire table can be obtained from the authors upon request). In particular, Social Concern, Strategic Position and Internal Factors presented the highest centrality indices (i.e. 29.90, 26.99 and 26.80, respectively). These pertain to issues such as the provision of capital for socially responsible businesses, charitable donations or support for minorities in what pertains to social concerns; matters of image, brand value and reputation, leadership competencies and governance models with regard to strategic positioning; 
and questions relating to compliance with laws and regulations, information transparency, and having long term vision in association to internal factors. Albeit grounded on a different methodological basis, these findings are consistent with the results of Bouma et al. (2001) and Fatemi and Fooladi (2013). The findings are also consistent with previous work (e.g. Ferreira et al. 2012; Rebai et al. 2012) in what pertains to the importance of Human Resources to achieve sustainable banking.

While most of the criteria included in the FCM are not new, the completeness of the cognitive structure created allowed important details to be detected, which might otherwise easily be overlooked. For instance, the use of social media to disseminate good practices, or the development of specific solutions/environmentally aligned products ( $c f$. Fig. 5). In fact, there was a generalized consensus among the panel members regarding the fact that some of the criteria included in the FCM are rarely considered in current sustainability frameworks, but that the process of FCM development had allowed for their identification and characterization.

These results are, naturally, context-dependent, meaning that they could have been different had the panel of experts been another or had the session a different duration (for details, see Ferreira et al. 2014). However, it is important to note that in addition to the results themselves, the approach followed allowed for discussion among experts and promoted a deeper understanding of the determinants that influence sustainable banking. Indeed, the way each criterion contributes to the calculation of the centrality indices offers real insight into the dynamics behind sustainable banking, supporting the premise that "FCMs are simple, yet powerful tools for modeling and simulation of dynamic systems, based on domain-specific knowledge and experience" (Papageorgiou et al. 2012: 45).

The major determinants of sustainable banking as resulting from the FCM can represent important inputs in planning policies and managerial initiatives regarding the practical application of sustainable strategies. In particular, the key determinants (in this case, Social Concern, Strategic Position and Internal Factors) can be related to a key company's business objectives in a new FCM. Through simulation, based on neural network computation, several scenarios can be analyzed. For example, what happens to business objectives if social or environmental concerns are strongly enforced? Or if instead, there is a strong focus on internal factors? The results of such simulations provide insights about the rankings of the variables in relation to one another, and as such can constitute useful inputs for planning effective policies and managerial choices for sustainable business growth. From a methodological point of view, the results obtained in this study can also provide a knowledge base to inform, for instance, the application of multiple criteria decision analysis (MCDA) techniques to select the most sustainable bank (for discussion and/or further details on the integrated use of these methodologies, see Zavadskas, Turskis 2011; Zavadskas et al. 2014; Mardani et al. 2015; Ferreira et al. 2016; Jalali et al. 2016).

As Salmeron (2009: 275) points out, "from an Artificial Intelligence perspective, FCMs are supervised learning neural systems, where as more and more data is available to model the problem, the system becomes better at adapting itself and reaching a solution". Indeed, the results obtained in this study suggest that FCMs hold great potential for operational planning and improvement of sustainable banking, which is of prime concern for banks and society at large. 


\subsection{System validation, limitations and recommendations}

The knowledge-based representation of sustainable banking resulting from the construction of the FCM allowed the group members to: (1) identify objective and subjective determinants of sustainable banking; (2) identify key feedback loops and analyze the dynamics of the system; (3) engage in meaningful discussion throughout the meeting; and (4) provide insights that have improved our understanding of sustainable banking.

Although consistent with the literature, and validated by consensus of the expert panel members, this proposal is not without its limitations. As already pointed out, the process followed is subjective in nature and its context-dependence discourages direct extrapolations. In addition, and as argued by Stach et al. (2005: 372), "FCM development methods are far from being complete and well-defined [...] the development of FCM models almost always relies on human knowledge [... and are] strongly depend on subjective beliefs of expert(s) from a given domain". Balancing pros and cons, it should be underlined, however, that these limitations are arguably more than compensated by the exchange of ideas underlying the negotiation process, and by the insights brought to the system by the panel of experts, which might go undetected by simple applications of statistical methods alone ( $c f$. Stach et al. 2005). In addition, due to the constructivist nature of FCMs, our framework is flexible enough to accommodate new information, allowing decision makers to immediately assess the impact of new criteria on system outcomes.

\section{Conclusions}

There has been significant progress in the field of sustainable banking in recent times, concomitant to increasing interest in the topic and pressure for banks to consider sustainability in their activities at all levels. Notwithstanding, existing contributions fall short of clearly identifying the cause-and-effect relationships between the determinants of sustainable banking. A knowledge-based representation of sustainable banking has been identified as a research priority for the development of sophisticated decision support systems, because, as noted by Kim and Lee (1998: 303), "knowledge engineering is one of the most important tasks in developing expert systems. One of the primary objectives [...] is to develop a complete, consistent and unambiguous description of the knowledge base".

Based on this premise, and taking a constructivist standpoint, this paper made use of FCMs to, through the discussion and negotiation of a group of experts: (1) identify the main determinants of sustainable banking; (2) define them; (3) determine their interactions; (4) create a visual map of the system as a whole; and (5) analyze its dynamics. Although FCMs allow static, dynamic and loop analyses of the results to be produced, the main concern in the current study was to identify the cognitive structure of factors affecting sustainable baking. The constructivist epistemological stance assumed allowed our contribution to be differentiated from the extant literature, which has generally been more focused on the analysis of variable dynamics, rather than on knowledge sharing and representation per se. 
The results of this study can be expected to contribute to the literature, not only in what refers to sustainability strategies in the banking sector, strategic knowledge asset management and operational research, but also at a methodological level. By reducing the number of omitted criteria and increasing our understanding of the relationships between variables, this study strengthens previous claims that fuzzy logics and FCMs can provide an important alternative for overcoming some of the limitations associated with the methodologies currently most in use in the industry ( $c f$. Keršuliene், Turskis 2011; Salmeron, Gutierrez 2012; Salmeron, Lopez 2012; Glykas 2013). Indeed, sustainable banking decisions are characterized as being complex, subjective, and fuzzy in themselves; which makes them a particularly appropriate context for the application of knowledge-based frameworks. FCMs, as neuro-fuzzy systems, are able to incorporate expert knowledge; and as such hold powerful and far-reaching potential to analyze and model complex decision problems, where there is scarcity of information or data, as is often the case in sustainable banking situations.

As discussed, our proposal is context-depend and not without its own limitations. Therefore, it would be of interest for future research to: (1) replicate the study with another set of banking experts, in order to determine the robustness of the research outcomes; (2) replicate the process in another country context; (3) compare the results obtained with those from different methodological applications (see Salmeron et al. 2012; Xu, Ouenniche 2012; Zavadskas et al. 2014; Mardani et al. 2015); (4) extend the proposal to other contexts; or (5) involve in the FCM building process a wider spectrum of bank stakeholders with different values and preferences. Any such advance in our understanding of sustainable banking can be used to create (or improve) new strategies.

\section{Acknowledgeents}

Previous, non-copyrighted and less complete versions of this paper were presented at the 2014 IFKAD International Conference, held in Matera, Italy, June 2014, and 2015 BAI International Conference, held in Macau, China, July 2015. The authors gratefully acknowledge the superb contribution and infinite willingness of the expert panel members. Institutional and facility support from the ISCTE Business School, University Institute of Lisbon, Portugal, is also acknowledged.

\section{References}

Ackermann, F.; Eden, C. 2001. SODA - Journey making and mapping in practice, in J. Rosenhead, J. Mingers (Eds.). Rational analysis for a problematic world revisited: problem structuring methods for complexity, uncertainty and conflict. $2^{\text {nd }}$ ed. Chichester: John Wiley \& Sons, 43-60.

Bouma, J.; Klinkers, L.; Jeucken, M. 2001. Sustainable banking: the greening of finance. UK: Greenleaf Publishing.

Canas, S.; Ferreira, F.; Meidute-Kavaliauskienè, I. 2015. Setting rents in residential real estate: a methodological proposal using multiple criteria decision analysis, International Journal of Strategic Property Management 19(4): 368-380. https://doi.org/10.3846/1648715X.2015.1093562 
Carlucci, D.; Ferreira, F.; Schiuma, G.; Jalali, M.; António, N. 2014. A knowledge-based representation of sustainable banking: insights from fuzzy cognitive mapping, in $9^{\text {th }}$ International Forum on Knowledge Asset Dynamics (IFKAD-2014), 12-14 June 2014, Matera, Italy, 1837-1855.

Carlucci, D.; Schiuma, G.; Gavrilova, T.; Linzalone, R. 2013. A fuzzy cognitive map based approach to disclose value creation dynamics of ABIs, in $8^{\text {th }}$ International Forum on Knowledge Asset Dynamics (IFKAD-2013), 12-14 June 2013, Zagreb, Croatia, 207-219.

Carmeli, A. 2004. Assessing core intangible resources, European Management Journal 22(1): 110-122. https://doi.org/10.1016/j.emj.2003.11.010

Carvalho, J. 2013. On the semantics and the use of fuzzy cognitive maps and dynamic cognitive maps in social sciences, Fuzzy Sets and Systems 214: 6-19. https://doi.org/10.1016/j.fss.2011.12.009

Cole, R. 2011. Motivating stakeholders to deliver environmental change, Building Research \& Information 39(5): 431-435. https://doi.org/10.1080/09613218.2011.599057

Dias, S.; Hadjileontiadou, S.; Hadjileontiadis, L.; Diniz, J. 2015. Fuzzy cognitive mapping of LMS users' quality of interaction within higher education blended-learning environment, Expert Systems with Applications 42(21): 7399-7423. https://doi.org/10.1016/j.eswa.2015.05.048

Eden, C.; Ackermann, F. 2001. SODA - The principles, in J. Rosenhead, J. Mingers (Eds.). Rational analysis for a problematic world revisited: problem structuring methods for complexity, uncertainty and conflict. $2^{\text {nd }}$ ed. Chichester: John Wiley \& Sons, 21-41.

Fatemi, A.; Fooladi, I. 2013. Sustainable finance: a new paradigm, Global Finance Journal 24(2): 101113. https://doi.org/10.1016/j.gf.2013.07.006

Ferreira, F.; Jalali, M. 2015. Identifying key determinants of housing sales and time-on-the-market (TOM) using fuzzy cognitive mapping, International Journal of Strategic Property Management 19(3): 235-244. https://doi.org/10.3846/1648715X.2015.1052587

Ferreira, F.; Jalali, M.; Ferreira, J. 2016. Integrating qualitative comparative analysis (QCA) and fuzzy cognitive maps (FCM) to enhance the selection of independent variables, Journal of Business Research 69(4): 1471-1478. https://doi.org/10.1016/j.jbusres.2015.10.127

Ferreira, F.; Jalali, M.; Ferreira, J.; Stankevičienè, J.; Marques, C. 2015. Understanding the dynamics behind bank branch service quality in Portugal: pursuing a holistic view using fuzzy cognitive mapping, Service Business 10(3): 469-487. https://doi.org/10.1007/s11628-015-0278-X

Ferreira, F.; Santos, S.; Rodrigues, P. 2011. Adding value to bank branch performance evaluation using cognitive maps and MCDA: a case study, Journal of the Operational Research Society 62(7): 1320-1333. https://doi.org/10.1057/jors.2010.111

Ferreira, F.; Santos, S.; Rodrigues, P.; Spahr, R. 2014. Evaluating retail banking service quality and convenience with MCDA techniques: a case study at the bank branch level, Journal of Business Economics and Management 15(1): 1-21. https://doi.org/10.3846/16111699.2012.673504

Ferreira, F.; Spahr, R.; Santos, S.; Rodrigues, P. 2012. A multiple criteria framework to evaluate bank branch potential attractiveness, International Journal of Strategic Property Management 16(3): 254276. https://doi.org/10.3846/1648715X.2012.707629

Filipe, M.; Ferreira, F.; Santos, S. 2015. A multiple criteria information system for pedagogical evaluation and professional development of teachers, Journal of the Operational Research Society 66(11): 1769-1782.

Garland, R.; Gendall, P. 2004. Testing Dick and Basu's customer loyalty model, Australasian Marketing Journal 12(3): 81-87. https://doi.org/10.1016/S1441-3582(04)70108-1

Gavrilova, T.; Carlucci, D.; Schiuma, G. 2013. Art of visual thinking for smart business education, in $8^{\text {th }}$ International Forum on Knowledge Asset Dynamics (IFKAD-2013), 12-14 June 2013, Zagreb, Croatia, 1754-1761.

Glykas, M. 2013. Fuzzy cognitive strategic maps in business process performance measurement, Expert Systems with Applications 40(1): 1-14. https://doi.org/10.1016/j.eswa.2012.01.078 
Jalali, M.; Ferreira, F.; Ferreira, J.; Meidutė-Kavaliauskienė, I. 2016. Integrating metacognitive and psychometric decision making approaches for bank customer loyalty measurement, International Journal of Information Technology and Decision Making 15(4): 815-837. https://doi.org/10.1142/S0219622015500236

Jeucken, M.; Bouma, J. 1999. The changing environment of banks, Greener Management International 27: 21-35.

Kang, B.; Deng, Y.; Sadiq, R.; Mahadevan, S. 2012. Evidential cognitive maps, Knowledge-Based Systems 35(15): 77-86. https://doi.org/10.1016/j.knosys.2012.04.007

Kardaras, D.; Mentzas, G. 1997. Using fuzzy cognitive maps to model and analyse business performance assessment, in $2^{\text {nd }}$ Annual International Conference on Industrial Engineering Applications and Practice, 12-15 November 1997, San Diego, California, USA, 63-68.

Kauko, T. 2010. Value stability in local real estate markets, International Journal of Strategic Property Management 14(3): 191-199. https://doi.org/10.3846/ijspm.2010.14

Keršuliene, V.; Turskis, Z. 2011. Integrated fuzzy multiple criteria decision making model for architect selection, Technological and Economic Development of Economy 17(4): 645-666. https://doi.org/10.3846/20294913.2011.635718

Kim, H.; Lee, K. 1998. Fuzzy implications of fuzzy cognitive map with emphasis on fuzzy causal relationship and fuzzy partially causal relationship, Fuzzy Sets and Systems 97(3): 303-313. https://doi.org/10.1016/S0165-0114(96)00349-1

Kok, K. 2009. The potential of fuzzy cognitive maps for semi-quantitative scenario development, with an example from Brazil, Global Environmental Change 19(1): 122-133. https://doi.org/10.1016/j.gloenvcha.2008.08.003

Kosko, B. 1986. Fuzzy cognitive maps, International Journal of Man-Machine Studies 24(1): 65-75. https://doi.org/10.1016/S0020-7373(86)80040-2

Kosko, B. 1992. Neural networks and fuzzy systems. New Jersey: Prentice-Hall.

Lopez, C.; Salmeron, J. 2013. Dynamic risks modelling in ERP maintenance projects with FCM, Information Sciences 256: 25-45. https://doi.org/10.1016/j.ins.2012.05.026

Mardani, A.; Jusoh, A.; Zavadskas, E. 2015. Fuzzy multiple criteria decision-making techniques and applications: two decades review from 1994 to 2014, Expert Systems with Applications 42(8): 41264148. https://doi.org/10.1016/j.eswa.2015.01.003

Martins, V.; Filipe, M.; Ferreira, F.; Jalali, M.; António, N. 2015. For sale... but for how long? a methodological proposal for estimating time-on-the-market, International Journal of Strategic Property Management 19(4): 309-324. https://doi.org/10.3846/1648715X.2015.1072746

Mazlack, L. 2009. Representing causality using fuzzy cognitive maps, in Annual Meeting of the North American Fuzzy Information Processing Society (NAFIPS-2009), 14-17 June 2009, Cincinnati, Ohio, USA, 1-6. https://doi.org/10.1109/nafips.2009.5156434

Pan, Y.; Sheng, S.; Xie, F. 2012. Antecedents of customer loyalty: an empirical synthesis and reexamination, Journal of Retailing and Consumer Services 19(9): 150-158.

https://doi.org/10.1016/j.jretconser.2011.11.004

Papageorgiou, E.; Roo, J.; Huszka, C.; Colaert, D. 2012. Formalization of treatment guidelines using fuzzy cognitive maps and semantic web tools, Journal of Biomedical Informatics 45(1): 45-60. https://doi.org/10.1016/j.jbi.2011.08.018

Papageorgiou, E.; Salmeron, J. 2013. A review of fuzzy cognitive maps research during the last decade, IEEE Transactions on Fuzzy Systems 21(1): 66-79. https://doi.org/10.1109/TFUZZ.2012.2201727

Peña, A.; Sossa, H.; Gutiérrez, A. 2008. Causal knowledge and reasoning by cognitive maps: pursuing a holistic approach, Expert Systems with Applications 35(1/2): 2-8. 
Peng, Z.; Peng, J.; Zhao, W.; Chen, Z. 2015. Research on FCM and NHL based high order mining driven by big data, Mathematical Problems in Engineering 2015: 1-7. https://doi.org/10.1155/2015/802505

Peng, Z.; Wu, I.; Chen, Z. 2016. Research on steady states of fuzzy cognitive map and its application in three-rivers ecosystem, Sustainability 8: 1-10. https://doi.org/10.3390/su8010040

Ramos, J.; Ferreira, F.; Monteiro Barata, J. 2011. Banking services in Portugal: a preliminary analysis to the perception and expectations of front office employees, International Journal of Management and Enterprise Development 10(2/3): 188-207. https://doi.org/10.1504/IJMED.2011.041549

Rebai, S.; Azaiez, B.; Saidane, D. 2012. Sustainable performance evaluation of banks using a multiattribute utility model: an application to French banks, Procedia Economics and Finance 2: 363-372. https://doi.org/10.1016/S2212-5671(12)00098-6

Reis, J.; Ferreira, F.; Monteiro Barata, J. 2013. Technological innovation in banking services: an exploratory analysis to perceptions of the front office employee, Problems and Perspectives in Management 11(1): 34-49.

Salmeron, J. 2009. Augmented fuzzy cognitive maps for modelling LMS critical success factors, Knowledge-Based Systems 22(4): 275-278. https://doi.org/10.1016/j.knosys.2009.01.002

Salmeron, J. 2012. Fuzzy cognitive maps for artificial emotions forecasting, Applied Soft Computing 12(12): 3704-3710. https://doi.org/10.1016/j.asoc.2012.01.015

Salmeron, J.; Gutierrez, E. 2012. Fuzzy grey cognitive maps in reliability engineering, Applied Soft Computing 12(12): 3818-3824. https://doi.org/10.1016/j.asoc.2012.02.003

Salmeron, J.; Lopez, C. 2012. Forecasting risk impact on ERP maintenance with augmented fuzzy cognitive maps, IEEE Transactions on Software Engineering 38(2): 439-452. https://doi.org/10.1109/TSE.2011.8

Salmeron, J.; Vidal, R.; Mena, A. 2012. Ranking fuzzy cognitive maps based scenarios with TOPSIS, Expert Systems with Applications 39(3): 2443-2450. https://doi.org/10.1016/j.eswa.2011.08.094

Stach, W.; Kurgan, L.; Pedrycz, W.; Reformat, M. 2005. Genetic learning of fuzzy cognitive maps, Fuzzy Sets and Systems 153(3): 371-401. https://doi.org/10.1016/j.fss.2005.01.009

Stankevičiené, J.; Nikonorova. 2014. Sustainable value creation in commercial banks during financial crisis, Procedia - Social and Behavioral Sciences 110(1): 1197-1208. https://doi.org/10.1016/j.sbspro.2013.12.966

Stephens, C.; Skinner, C. 2013. Banks for a better planet? The challenge of sustainable social and environmental development and the emerging response of the banking sector, Environmental Development 5: 175-179. https://doi.org/10.1016/j.envdev.2012.11.011

Stylios, C.; Groumpos, P. 1999. Fuzzy cognitive maps: a model for intelligent supervisory control systems, Computers in Industry 39(3): 229-238. https://doi.org/10.1016/S0166-3615(98)00139-0

Tsadiras, A.; Kouskouvelis, I.; Margaritis, K. 2003. Using fuzzy cognitive maps as a decision support system for political decisions, in $8^{\text {th }}$ Panhellenic Conference on Informatics (PCI-2001), 8-10 November 2003, Nicosia, Cyprus, 172-182. https://doi.org/10.1007/3-540-38076-0_12

Vidal, R.; Salmeron, J.; Mena, A.; Chulvi, V. 2015. Fuzzy cognitive map-based selection of TRIZ trends for eco-innovation of ceramic industry products, Journal of Cleaner Production 107: 202-214. https://doi.org/10.1016/j.jclepro.2015.04.131

$\mathrm{Wu}, \mathrm{H}$. 2012. Constructing a strategy map for banking institutions with key performance indicators of the balanced scorecard, Evaluation and Program Planning 35(3): 303-320. https://doi.org/10.1016/j.evalprogplan.2011.11.009

$\mathrm{Xu}$, B.; Ouenniche, J. 2012. Performance evaluation of competing forecasting models: a multidimensional framework based on MCDA, Expert Systems with Applications 39(9): 8312-8324. https://doi.org/10.1016/j.eswa.2012.01.167 
Yaman, D.; Polat, S. 2009. A fuzzy cognitive map approach for effect-based operations: an illustrative case, Information Sciences 179(4): 382-403. https://doi.org/10.1016/j.ins.2008.10.013

Yesil, E.; Ozturk, C.; Dodurka, M.; Sakalli, A. 2013. Fuzzy cognitive maps learning using artificial bee colony optimization, in IEEE International Conference on Fuzzy Systems (Fuzz-IEEE), 07-10 July 2013, Hyderabad, India, 1-8.

Zavadskas, E.; Turskis, Z. 2011. Multiple criteria decision making (MCDM) methods in economics: an overview, Technological and Economic Development of Economy 17(2): 397-427. https://doi.org/10.3846/20294913.2011.593291

Zavadskas, E.; Turskis, Z.; Kildiene, S. 2014. State of art surveys of overviews on MCDM/MADM methods, Technological and Economic Development of the Economy 20(1): 165-179. https://doi.org/10.3846/20294913.2014.892037 